\title{
The Adaptation Deficit in Water Resource Management
}

\author{
Ian Burton and Elizabeth May
}

\section{The adaptation deficit}

As human populations and material wealth expand, the demands upon limited water resources inevitably increase. The adaptive response is to judiciously expand supplies where this can be achieved without further irreversible detriment to the resource and to manage water demand by more efficient and equitable use and by the modification of water management practices. Failure to do this at a fast enough rate is exacerbating water problems in all regions of the earth. The water resources of the earth are being used in an unsustainable way and the gap between sustainable use and present practice is the current "adaptation deficit". This situation is getting worse with the advent of anthropogenic climate change, such that there is also a looming future adaptation deficit. This article describes some of the features of this deficit and presents perspectives from the science community, (the Intergovernmental Panel on Climate Change, IPCC) and the negotiations under the UN Framework Convention on Climate Change (UNFCCC). It then offers a diagnosis of some of the major obstacles to reform in water resources management, within the Climate Convention and in the water management field, with some current Canadian examples. The article concludes with a few suggestions of how the adaptation deficit may addressed by improvements in the emerging adaptation regime (see also Pachauri, Denton, Huq and Reid and Agrawala, this Bulletin, for climate and water-related issues in developing countries).

\section{Science view: the Intergovernmental Panel on Climate Change}

After decades of policy development in sound water management, not to mention a special United Nations Decade dedicated to access to clean water, millions of people globally still lack basic water security. Tens of thousands of children die every day due to water-borne diseases. Ground water resources are being drawn down in many places at rates that far exceed natural replenishment. Losses from floods and droughts are increasing rapidly. These and other present-day problems of water management and use have been exhaustively catalogued in international fora including the World Water Forum (Kyoto 2003) and the World Summit on Sustainable Development, Johannesburg in 2003. Despite this attention, progress remains slow and programmes are poorly funded in relation to actual needs. The situation is about to get worse. The threat of global climate change is real and some changes have already been observed (IPCC 2001). While nations debate, or evade their obligations to reduce greenhouse gas ( $G H G$ ) emissions, the impacts of climate change threaten areas not yet tied in the public mind with the threat.

The most recent assessment by the Intergovernmental Panel on Climate Change (IPCC 2001) devotes a chapter (Ch. 4) to 'hydrology and water resources'. The chapter presents an appropriately cautious summary of the peer reviewed literature and concludes as follows:

1. Streamflow volume (both increases and decreases) is changing in many regions but the observed trends cannot all be definitively attributed to changes in regional temperature or precipitation.

Comment: Presumably many of the trends can be attributed to climate change (temperature and precipitation) but the chapter does not say so directly.

2. Widespread accelerated glacier retreat and shifts in streamflow timing (including peak streamflow) in many areas from spring to winter are more likely to be associated with climate change.

Comment: The seasonality of flow can be more important that total annual volume. Spring run- 
off plays a crucial role in riverine ecosystems and in water supply for irrigation and other uses. If this season of peak flow arrives the consequences for human uses can be severe.

3. Glacier retreat is likely to continue and many small glaciers may disappear.

Comment: Glaciers play an important role in maintaining downstream flow during the summer or at times when the flow would otherwise be much reduced.

4. The effects of changes in streamflow and groundwater recharge are not consistent in magnitude between the various General Circulation Models (GCM) climate projections and in some parts of the world the direction of change is uncertain.

Comment: This uncertainty about the magnitude and even the direction of climate-induced changes is often cited as a reason for inaction.

5. Water quality is likely generally to be degraded by higher water temperature, but this may be regionally offset by increased flows.

Comment: The caveat applies more when the increased flows are in the period (summer) of higher temperatures.

6. Flood magnitude and frequency are likely to increase in most regions and low flows are likely to decrease in many regions.

Comment: Interpreted this means that both floods and droughts are likely to increase in both frequency and magnitude often in the same place. Trends in streamflow measured and reported in terms of average annual or seasonal flow tend to mask greater short-term variability.

7. Demand for water generally is increasing as a result of population growth and economic development. Climate change is unlikely to have a large effect on municipal and industrial demands but may substantially affect irrigation withdrawals.

Comment: Increased demand for water results both from climate change and socio-economic change.

8. The impact of climate change on water resources depends not only on the climate itself but also on system characteristics, changing pressures on the system, how the management of the system evolves and what adaptation to climate change are implemented.

Comment: It is significant that non-climatic changes may have a greater impact on water resources than climate change. In this sense climate change presents an incremental challenge to water resources management.

9. Climate change challenges existing water resources management practices by adding additional uncertainty. Integrated water resources management will enhance the potential for adaptation to climate change.

Comment: This suggests that the enhanced potential for adaptation depends upon the use of an integrated approach.

10. Adaptive capacity (specifically, the ability to implement integrated water resources management), however, is distributed very unevenly across the world.

Comment: This suggests that capacity to respond is going to be a crucial variable in determining the net impacts of climate change on water resources management.

The chapter is more concerned with distinguishing the impacts of climate change than with what the climate might have been in the absence of climate change (i.e. distinguishing anthropogenically-induced climate change from climate variability). The water management problems associated with existing climate including climate variability and extremes are a matter of incidental background and not the centre of attention. This is correct, legitimate and to be expected, because the task of the IPCC is to assess the science of climate change and not current climate. Thus while the IPCC offers an assessment of climate change in the water resources field, it is a view of the climate change increment rather than an assessment of the problem as a whole. The chapter is also focused on the direct impacts on future water flows in quantitative and qualitative terms and pays little attention to the secondary knock-on effects on food production, natural ecosystems, human health, natural disasters (floods and droughts) and on poverty and economic development. To the development specialists therefore the IPCC water chapter may come across as a rather complacent, even perhaps reassuring assessment. Nothing very dramatic is reported and the message is carefully balanced and nuanced. It is true that some of the second order impacts are considered in other chapters on agriculture, health etc., but even here the message is restrained and cautiously expressed. In the case of agriculture, for 
example, the IPCC concludes that with and without climate change the downward trend in real commodity prices in the twentieth century is likely to continue into the twenty-first century and that the impacts of climate change on agriculture after adaptation are estimated to result in small percentage changes in global income, which tend to be positive for a moderate global warming. Imagine! As far as agriculture is concerned moderate climate change may increase global income!

This type of reassuring message is repeated many times in the sectoral chapters of the IPCC Third Assessment and as pointed out by Huq and Reid in this Bulletin also pervades thinking in some parts of the donor community as it approaches the issue of funding climate adaptation. When the problem of climate change is disaggregated into potential impacts on specific targets in specific places any sense of urgency tends to evaporate. Contrast this with the sense of alarm and global threat presented by environmentalists, the Green Parties, the reinsurance industry and many government agencies and ministries of environment and meteorology and one may begin to wonder where the truth lies.

\section{The climate convention}

One source of this lack of clarity and consensus can be traced back to the perception of the climate change issue that is reflected in the United Nations Framework Convention on Climate Change. (UNFCCC, www.unfccc.int). The Convention was negotiated in the period 1989-92, as the third in a series of major regional and global atmospheric issues. Acid precipitation in Europe and North America and global ozone layer depletion were both caused by industrial emissions of gases (sulphur dioxide in the case of acid rain and chlorofluorocarbons in the ozone layer case). The success of dealing with these issues by international conventions that limited the emissions of the offending gases set an impressive and powerful precedent for negotiations on global warming. Climate change came to be seen as a pollution issue. The appropriate solution therefore is to be found in pollution control. Hence Article 2 of the Framework Convention:

The ultimate objective of this Convention and any related legal instruments that the Conference of the Parties may adopt is to achieve, in accordance with the relevant provisions of the Convention, stabilization of greenhouse gas concentrations in the atmosphere at a level that would prevent dangerous atmospheric interference with the climate system. Such a level should be achieved within a time-frame sufficient to allow ecosystems to adapt naturally to climate change, to ensure that food production is not threatened and to enable economic development to proceed in a sustainable manner.

This Article of the Convention has had two far reaching consequences. First, it has fostered the assumption (largely unquestioned) that the solution to the climate change problem lies in the control of greenhouse gas emissions, commonly referred to as "mitigation". Second, it simplifies and distorts the fundamental nature of the climate problem. It presents the problem as a unidirectional relationship of cause and effect in which climate change is the cause or the driving variable and impacts on human society are the result. In this, climate change differs substantially in degree, if not in kind, from the other atmospheric problems of acid precipitation and ozone layer depletion. The consequences or impacts of climate change are the results of an interactive process in which human activities are interacting with the climate. In this sense it is misleading to refer to the "impacts" of climate change. The magnitude of the impacts can be attributed as much to human-generated vulnerability as to actual (human-generated) changes in climate. Failure to adapt water management well enough and rapidly enough accounts for a larger proportion (perhaps the overwhelming proportion) of the water problem than the impacts (actual and projected) of climate change.

This conclusion is expressed in the IPCC chapter on hydrology and water resources in conclusions 7 to 10 listed above. The chapter does not elaborate on these conclusions. The task of the IPCC is after all to provide an assessment of the science and not to draw policy conclusions. But the implication of conclusions 8, 9 and 10 cited above is especially clear. Much depends upon adaptation measures and improvements in water management and the capacity to implement them.

These questions are being addressed much more outside the Climate Convention and the IPCC than inside. At the World Water Forum (Kyoto 2003, www.world.water-forum3.com/2003/eng/press/ 


\section{Table 1: A comparison of the adaptation and mitigation regimes under the convention}

\begin{tabular}{lll} 
Mitigation & Adaptation \\
\hline 1. & Clearly defined & No definition \\
2. & Clearly stated objective & No objective stated \\
3. & Standard measures & No standard measures \\
& (emissions and concentrations) & (hardly any measures at all) \\
4. Baseline (1990 emissions) & No baseline \\
5. Global environmental benefits & Absence of global environmental benefits \\
6. Incremental costs calculable & Incremental costs not possible to calculate \\
7. Clear financial arrangement & Multiple, inconsistent and insufficient funding arrangements \\
8. Legal instrument (Kyoto) & No legal instrument \\
\hline
\end{tabular}

pressrelease/press0316-03.html) and at the United Nations Conference on Sustainable Development (Johannesburg 2002) the water management issues received a lot of attention. With few exceptions this attention did not focus on future climate change, but on such current problems as declining water resources, lack of access to safe drinking water, poor sanitation, inefficiency in water use, water rights and water transfers and supply and demand management and conflicts over the use and allocation of resources.

What emerges is that the world's water resources are already over-stretched and that unless present patterns and trends can be changed a major crisis is looming. This story contrasts sharply with the much cooler and even complacent, tone that prevails in some of the climate debates, especially in the IPCC. This stems largely from the limited mandate of the IPCC and the ultimate objective of the Climate Convention which are directed towards the incremental impacts of anthropogenic climate change.

In the context of the Climate Convention and the IPCC, the actions proposed to cope with the impacts of climate change are referred to as "adaptation" (see conclusions 8, 9 and 10 above). Many of these actions (policies and measures) are needed now to cope with current water resource problems. Although these actions have not been and are not now commonly referred to as "adaptation" many of them are in fact very similar if not mostly identical. The Climate Convention has focused attention on the control of greenhouse gas emissions (mitigation) and on adaptation to future climate change. What is needed however from a global development perspective is adaptation now.
Recognition of this has led the developing country Parties to the UNFCCC to press for financial assistance to help meet the costs of adaptation and to attempt to focus the negotiations about climate change on issues of poverty, equity and development presented, or one might even say "disguised" as adaptation to climate change. Thus two perspectives on adaptation have emerged. In one view, (the pollutionist view) adaptation is a secondary consideration under the Climate Convention and only has a role to play in helping to determine what is "dangerous" according to Article 2, or in helping to determine the urgency for mitigation actions such as those embodies in the Kyoto Protocol. The second view might be called the development perspective. Here adaptation is made to stand for all that is wrong in the water management and development process. Implicitly all the deficiencies of water management, (among the other sectors), are attributed to the lack of adaptation or lack of financial (donor) support for adaptation under the Convention.

\section{Diagnosis and prescription}

There are broadly two directions in which solutions or improvements may be sought (Burton and van Aalst 2004). Adaptation under the Climate Convention could be treated more seriously and the negotiations could address the creation of a more coherent adaptation regime. Second, more rapid progress could be made in the reforms and innovations in water management as has been proposed in the World Water Forum and elsewhere (Bergkamp et al. 2003).

The adaptation regime that has been built up under the Climate Convention is far too diffuse and 
unfocused. There is no clear definition of adaptation. No objectives are stated for adaptation except to help in determining what is 'dangerous anthropogenic interference with the climate system'. A comparison of the adaptation regime with the mitigation regime (Table 1 ) reveals the unsatisfactory state of adaptation within the Convention.

The implication of this comparison is that progress on adaptation under the Climate Convention would be facilitated by the development of a more coherent adaptation regime. Almost inevitably this means the eventual development of some sort of legal instrument such as an Adaptation Protocol. The prior questions that need to be answered are not at this stage a matter for negotiation but a matter for research and intellectual creativity. What is needed therefore is a new mechanism at arms length from the Convention where the adaptation issues of definition, objectives, baseline, measurements and so forth could be explored and specific alternatives developed to the stage where their final form can be negotiated.

Outside the Climate Convention the reform movement in the water management sector, especially the development of more integrated water management should continue with all due speed. Some of the more fundamental reasons for this have to do with such human failings as the existence and persistence of powerful vested interests; wishful thinking; lack of imagination; and the uncertainty excuse.

\subsection{Vested interests}

When speaking of vested interests in the climate debate the usual suspects are the fossil fuel interests, particularly the coal and oil lobbies and the associated industries that rely on cheap supplies, such as the power generation and automobile industries. Remarkably, the solid front presented by these interests is cracking and there are numerous examples where the private sector is taking climate change seriously and preparing through research and development and changing standards to lead the move to the new economy of energy efficiency, fuel switching and renewable. The vested interests that concern us are to be found elsewhere.

These include agencies with significant intellectual investment in the status quo. Models and methods of poverty alleviation and development do not yet take the climate change threat and the adaptation deficit seriously.
Compared to the immediacy of the HIV/AIDS crisis, calls to address the challenge of adaptation to climate change seem like a frivolous distraction.

There are also many who benefit from the present patterns of water use, water management and water allocation that stand to lose if changes are made. Very often the professional water managers know and understand well what is needed. Desirable actions are blocked by vested interests in the status quo.

\subsection{Wishful thinking}

On climate change and on water, large industrial developments are undertaken with the assumption that current water regimes and access to large volumes of water, will remain more or less the same. In Canada, the Canadian Environmental Assessment Agency has published, Incorporating Climate Change Considerations in Environmental Assessment: General Guidance for Practitioners (CEAA 2003). The document was developed through a federalprovincial territorial committee. It requires that assessment include a two-pronged approach to climate change:

- That those projects contributing to greenhouse gas emissions be assessed in light of carbon constraints.

- That projects that may experience impacts from the changing climate regime be examined in light of those impacts.

The Alberta Energy and Utilities Board has concluded it will ensure the CEAA guidelines are followed in future Alberta hearings (Alberta 2004). But, for the most part, major industrial expansions, whether in the Athabasca tar sands, where every produced barrel of oil consumes in the order of six barrels of water in processing, or in hydroelectric expansions, are taking place without an adequate, or often any, attempt to review the climate data in terms of the projections from general circulation models, or observed trends.

The glacier-fed Athabasca River is already showing significant reductions in flow, but project after project has been approved by the Alberta Department of the Environment requiring huge water withdrawals over decades. These approvals have, to date, been granted without any analysis of the threat to water supply in coming decades.

Manitoba Hydro recently submitted an environmental impact statement for a hydroelectric 
project, the Wuskwatim Generation Project, in the northern part of the province. The project has an anticipated one hundred year life span, yet in the EIS it claimed:

Due to the level of uncertainty relating to the potential effects of climate change, Manitoba Hydro cannot project a specific climate change scenario for the Wuskwatim Generation Project Area. (CEAA 2003)

It is no doubt true that the greater the level of localised detail required in climate modeling, the less certain is the result. Nevertheless, there are some observed existing trends. These trends are consistent with larger scale global climate models. One of the emerging areas of increased confidence about our understanding of the relationship between human-generated GHG and destabilisation of global climate comes as a result of finding that models of climate change track very well along observed impacts.

There has not been a great deal of work on observed impacts on water resources from existing levels of climate change in northern Manitoba, but there has been some (Zhang et al. 2001). This research demonstrates that generally, across Canada, annual mean streamflow has decreased. This was particularly a factor in southern Canada due to increased evaporation. Northern rivers, such as the Athabasca, which are glacier-fed, also show significant decline. In the study, northern Manitoba is also showing signs of changes in streamflow. Between 1957 and 1996, there are seasonal trends in monthly mean streamflow, with declines, although weak statistically, in April and small increases in September. The same trends hold true for daily mean streamflow.

It is only wishful thinking, or blinkered denial, that can explain large investments being made in projects that may prove to be non-viable due to climate impacts.

In Canada, large changes are expected in water levels in the Great Lakes and St Lawrence Seaway, impacting on transportation and tourism as well as water quality. Sea level rise, but more particularly storm surges, have already impacted coastal regions. Reduced water flow is a threat to a wide range of human activities and mega-projects. Despite the CEAA directive to the contrary, the planners are still wearing rose-coloured glasses.

\subsection{Lack of imagination}

The water industry is notoriously compartmentalised into specialties devoted to different aspects of water management. This has led to repeated calls for a more integrated approach. (Bergkamp et al. 2003). Modest progress is being made in this direction by the industry, but now a much bigger challenge has arrived. There is a need to integrate analysis and solutions not just within the water industry, but together with climate change impacts in all water-using or water-dependent activities especially in agriculture, fisheries and health.

Such integration is not simply a question of building and testing integrated models. It is more a question of imagination to identify the secondary and indirect impacts of climate change, as they move from water to food, to health at the same time that other changes are affecting the vulnerability of systems. The analytical approach can mislead by Type I or Type II errors and by failure of imagination it can miss the point altogether. Cumulative and spillover effects are not only hard to trace, they are hard to identify in advance.

Again, there are some positive signs. Some industries are paying attention. A vice-president of a major coal-driven utility recently told a conference that his company had decided against buying water rights for hydroelectricity in the US south-west. And based on future climate change impacts, Trans-Alta decided the water flow would likely not be able to meet hydroelectric demands in the future. ${ }^{1}$

\subsection{The uncertainty excuse}

A number of these identified mental barriers to progress overlap. The "wishful thinking" problem is aided and abetted by the "uncertainty excuse" and the even more troubling persistence of outright denial. Those in denial are largely found within the fossil fuel industry and the Bush administration. Whether they are actually persuaded that greenhouse gases are not accelerating climate change, or merely wish to buy time for the last grab at fossil fuel profits is an open question. Certainly the pattern of industrial denial immediately before industry acceptance is well established. On the acid rain issue and on the threat of ozone depletion, the key responsible industries dedicated considerable effort to denying that there was any problem related to their activities. Reforms and adoption of new 
industrial methods occurred rapidly once governmental intention was clear.

The next step past denial, is the uncertainty excuse: 'We don't know precisely how things will change therefore let's wait and see'.

Nevertheless, for purposes of addressing the adaptation deficit, certain realities apply universally. With more than 30 per cent higher levels of carbon dioxide now than at any time in the last 160,000 years, we have altered the climate beyond the foreseeable (into centuries) future. Even with the most aggressive policies imaginable to move away from fossil fuels, levels of GHGs by atmospheric concentration are likely to continue to rise.

These facts translate into a "new normal" for climate (see also Scoones, this Bulletin). Previous patterns of rainfall, flooding, drought, etc. are no longer reliable indicators of future patterns. In fact, the one thing we can be sure of is that climate is to be increasingly unpredictable with more frequent and more severe extreme weather events. Greater certainty than that is not required for many sensible steps in adaptation strategies.

\section{Note}

1. Dr Robert Page, V-P, TransAlta, speaking at the Globe 2004 conference, 2 April 2004, Vancouver, confirmed in personal communication with E. May.

\section{References}

Alberta Energy Utilities Board, 2004, in the Canadian Natural Resources Ltd. Horizon Mine Decision, January

Bergkamp, G., Orlando, B. and Burton, I., 2003, Change: Adaptation of Water Resources Management to Climate Change, Gland, Switzerland: International Union for the Conservation of Nature and Natural Resources (IUCN)

Burton, I. and van Aalst, 2004, 'Look before you leap: a risk management approach for incorporating climate change adaptation in World Bank operations', Environment Department Working Paper, Washington, D.C.: World Bank Canadian Environmental Assessment Agency (CEAA), 2003, Incorporating Climate Change Considerations in Environmental Assessment:

\section{The adaptation deficit}

The problems of uncertainty, vested interests, wishful thinking and lack of imagination, are difficult to combat in the hypothetical world of future climate change. Yet, the longer-term climatic future is where much of the attention of the research community (IPCC) and the negotiators under the Climate Convention is focused. The place to confront the climate change issue is here and now. It is not difficult to identify the obstacles to adaptation if we focus on the current adaptation deficit. Nowhere is this more true and more obvious that in water management. The Climate Convention could be of more help and could provide useful leverage to help the progressive forces in water management. After all, the threat of climate change and the evidence of some existing climate change impacts provide a powerful additional reason for concern and accelerated action. In coming to terms with the current adaptation deficit and incorporating the future potential deficit in current water management investments a revised and more coherent adaptation regime under the Climate Convention could be a big help.

General Guidance for Practitioners, Ottawa: CEAA. Intergovernmental Panel on Climate Change (IPCC), 2001, Report of Working Group II. Impacts and Adaptation in the Context of Sustainable Development, Cambridge: University of Cambridge Press, Ch 4: 193-2334

Kyoto, 2003, Report of the Third World Water Forum March 16-23 2003, Wrap-up session: Water and Cimate, 17 March 2003, available at www.waterandclimate.org, accessed July 2003

World Summit on Sustainable Development, 2003, Report and Plan of Implementation, available at www.johannesburgsummit.org, accessd April 2004

Zhang, X.K., Harvey, D., Hogg, W.D. and Yuzyk, T.R., 2000, 'Trends in Canadian Streamflow', Water Resources Research, Vol 37 No 4: 987-98 